When I presented my prescription for 100 5-mg tablets of dexamphetamine to one of the local pharmacists a look of complete horror passed over his face. He rushed into an inner sanctum and reappeared after five minutes, still wearing a most sinister expression. I found later that he had telephoned his union for advice on how to handle this unique and ticklish situation. $\mathrm{He}$ explained that if he were to dispense these tablets we were entering into what was almost a criminal conspiracy. Certainly, he said, we would both receive an early visit by a Man from the Ministry. I crept out in a rather bemused state. Here we have a minority group in the profession who have "restricted," and in fact practically prohibited the sale of a legal and orthodox drug listed in the British Pharmacopeia and by so doing prejudicing the law of the land.

And now our crusaders are setting their sights at the barbiturates. They are not likely, I think, to gain the same success as they claim with the amphetamines because most stable-minded doctors will realize that it is better to have at their command two good hypnotics rather than one. In any case it is becoming clear that this group seems to be more interested in bringing about an amphetamine-free world and a barbituratefree world than in promoting the maximum peace of mind of every patient. A strange doctrine more appropriate to the pulpit than the corsulting room. But then, of course, we live in a strange world. - I am, etc.,

Sudbourne, Suffolk

OLIVER IVE

\section{Sports Injuries Clinics}

SIR,- - The case advanced for the development of sports injuries clinics by Dr. P. N Sperryn and Mr. J. G. P. Williams ( 9 August, p. 364) is untenable in my opinion. One cannot dispute the existence of sportspecific illness. Nor can one question the importance of understanding "the particular movements or habits involved" in making the specific anatomical and aetiological musculoskeletal diagnosis so necessary for an optimal outcome. However, the wide range of sporting activities preclude any one physician becoming familiar with more than a few. In addition the common idiosyncrasies of training and competitive techniques employed by different individuals within the same sport limit the usefulness of a mere familiarity with a sport and the statistically most likely injuries therein.

Fortunately, the musculoskeletal system has a limited repertoire of responses (for example, sprain, strain, inflammation) to the unlimited variety of macrotrauma and repetitive microtrauma to which it is subjected. Only the site and not the nature of the pathology is sport-specific. Also fortunately, the athlete is exquisitely aware of his own training regimen and competitive habits and in which phase of these his discomfort is most severe. Therefore an adequate history elicited by a conscientious physician working in the musculoskeletal field at large should solve as many difficult diagnostic and therapeutic problems as a stable of sportologists in special clinics. Many of the former group resent having these interesting, intelligent, highly motivated patients skimmed off their practices. The activities of many non-athletic groups produce equally activity-specific musculoskeletal problems. The data and philosophy presented by the authors justifying the special status of sport if extrapolated, should allow special status for other activities equally common and disabling. Will special clinics to meet the needs of the "weekend gardener" or the "salt water angler" be next?-I am, etc.,

R. L. KIRBY

Oxford Regional Rheumatic Diseases Research Centre, Stoke Mandeville Hospital,

Aylesbury, Bucks

SIR,-Dr. P. N. Sperryn and Mr. J. G. P. Williams (9 August, p. 364) are to be congratulated on pointing out the inadequacy of the facilities afforded in Britain today for treating sports injuries. Indeed, this lack forms part of the hiatus in our Health Service whereby no one consultant bears responsibility for the medical aspects of orthopaedics. I agree that no special sportsmen's clinics are required; for the athlete or ballet-dancer who sprains his back or his knee requires the same treatment as other people; the difference is in urgency and in the degree of fitness that needs to be restored. However, I would disagree about priority. As most of these accidents occur on a Saturday, an hour was for many years kept free at our Monday morning clinic at St. Thomas's for this purpose, not least for the members of the hospital's own teams.

The optimum treatment for damage to most muscles is deep massage. Given transversely, this retains (in recent cases) or restores (in chronic cases) the capacity of the muscle to broaden out painlessly as it contracts. For tendons deep friction is again paramount, particularly at the ankle and heel. The normal excursion of a ligament can be maintained by deep friction, which moves it to and fro over underlying bones in imitation of its normal behaviour. Sprains at the neck and back usually respond best to manipulation; hence sportsmen's frequent recourse to laymen. The emergence of the manipulating physiotherapist would render these men superfluous.

The orthopaedic physician must be prepared to train each fresh physiotherapist who joins his staff how to give effective friction to each localized soft-tissue lesion and how to manipulate joints, particularly spinal. This was my practice at St. Thomas's for over 30 years. The period off work and games for ordinary citizens no less than for sportsmen would be greatly curtailed if this policy gained widespread adoption. It was well worth the extra trouble and made for happy collaboration between surgeon, physician, and physiotherapists working as one team in the orthopaedic department.-I am, etc.,

Londor. W.1

JAMES CYRIAX

\section{Hostility to Kith and Kin}

SIR,-Is not the whole point of Dr. S. Behrman's article, "Hostility to Kith and Kin" (7 June, p. 538) that the hostility is towards kin and not kith?-I am, etc.,

\section{SI Units}

SIR,-At a recent meeting of the Brighton District Medical Advisory Committee the directive from the Department of Health and Social Security regarding the procedure for initiating the use of SI units in the National Health Service was presented. During the discussion it became apparent that though no direct advantage in the clinical care of the patient could be claimed for the new system many disadvantages and dangers could be cited. Also, at a time of great financial stringency a new system of measurement, with its attendant costs and inconvenience, was being forced upon clinicians without their opinions having been sought in any depth, if at all.

It was resolved therefore that: "This committee feels that it would be inappropriate to initiate the use of SI units in the hospitals of the Brighton District at this time and the District Management Team be informed accordingly." The matter was further discussed at the District Hospitals Medical Committee, when the resolution outlined above was unanimously supported.-I am, etc.,

AUSTIN BROWN
Chairman,
Brighton District Hospitals Medical Advisory
Committee,
Brighton District Hospitals Medical Committee

SIR,-The change to SI units is upon us, but need authors and editors make the change over even more complicated than necessary? In their article on cryptococcal meningoencephalitis (12 July, p. 75), Dr. R. A. Martin and others described the C.S.F. as containing $0.001 \times 10^{9} / 1$ lymphocytes. We are told that we must now accept the litre as the standard measure of volume, but why need authors or their editors increase the confusion by the use of this profusion of decimal places and powers of 10? Why not simply write $1 \times 10^{6} / 1$ ? We must not forget that when there is confusion of any sort the patient may suffer and may even occasionally die as a result. For this ever to happen as the result of an unnecessary change would be quite inexcusable. - I am, etc.,

Torbay Hospital

L. J. HAYEK Torquay

** The fault lay not with Dr. Martin and his colleagues but with us in converting their value of 1 lymphocyte $/ \mathrm{mm}^{3}$ into SI units. We agree that $1 \times 10^{6} / 1$ would have been more appropriate and are changing our conversion rules accordingly.-ED., B.M.F.

\section{Death during Dental Anaesthesia}

SIR,-I read with interest the comments made by Dr. J. G. Bourne (11 January, p. 93) and Dr. S. Mehta (27 April 1974, p. 224) on cases of death during dental anaesthesia. I should like to report a recent fatal case of severe unaccountable collapse following administration of anaesthesia in a dental chair.

A healthy young girl aged 11 needed dental extraction as she was suffering from an alveolar abscess and was in pain. Before anaesthesia I confirmed from the dental records that there was nothing in her medical history to contraindicate general anaesthesia. She had been in a car accident

H. DE Glanville in March 1974 and had had a splenectomy as a result. There was nothing else of note in the history 
The girl was brought into the surgery by one of the nursing attendants. She was not apprehensive and she sat down quietly in the dental chair semiupright $\left(45^{\circ}\right)$. There was nothing about her manner to make me at all suspicious that she was in any way unwell. The dentist then examined her mouth and inserted the dental prop and pack. I induced anaesthesia in the normal fashion with a mixture of $75^{\circ}$, nitrous oxide and $25 \%$ oxygen, using a mouth and nose piece with a pressure of $5 \mathrm{~mm} \mathrm{Hg}$. Induction was normal and smooth and after about 2 min I gave halothane, starting with 1 unit $(0.05 \%)$ on the vaporizer scale and gradually increasing to 2 units $\left(0 \cdot 5^{\circ}\right.$ ) $)$. The dentist then proceeded with the planned extraction of two teeth and the whole procedure was completed within $5 \mathrm{~min}$. I then discontinued the anaesthetic and the dentist took out the mouth prop and pack while I waited for the patient to recover from the anaesthetic.

After approximately $1 \mathrm{~min} I$ noticed that she became pale and her respiration shallow. I immediately felt for the radial pulse, but this was not palpable so at once I shouted "cardiac arrest." At the same time I lifted her from the chair and put her on the floor and started giving her external cardiac massage. I then asked the dentist to administer pure oxygen by mask. The patient started breathing rather irregularly, but I still could not feel the radial pulse so I administered an intravenous injection of $15 \mathrm{mg}$ of methylamphetamine while continuing the cardiac massage. Also an amhulance was summoned immediately. The first injection of methylamphetamine produced no response, so after $5 \mathrm{~min} I$ gave another $15 \mathrm{mg}$, all the time continuing external cardiac massage and oxygen. The ambulance arrived about $25 \mathrm{~min}$ after the call for it and before transferring the patient into the ambulance I gave another $15 \mathrm{mg}$ of methylamphetamine intravenously. The patient was transferred to the ambulance and I accompanied her to hospital, where I passed a cuffed endotracheal tube and administered oxygen with the Boyle's anaesthetic machine. Her treatment was then taken over by the medical staff of the hospital, but the improvement was transient and she died $6 \frac{1}{2}$ hours after the collapse. Post-mortem findings were negative.

It appears that the child had a vasovagal attack, and the cardiovascular collapse occurred without apparent cause or warning. I strongly support the explanation given by Dr. Mehta that "once peripheral vasodilatation has begun and blood pressure is falling the sitting position will increase cerebral oligaemia by gravitational pooling of blood in the dependent portions of the body and will further lead to reduced filling of the right atrium and cardiac output. There is no doubt that whatever the cause of hypotension its outcome in terms of brain damage or death of the patient is greatly influenced by the upright position traditionally used in dentistry." I agree with him that, though death during dental anaesthesia is rare, one could avoid these occasional fatalities by altogether abandoning the sitting position or by intensive monitoring while anaesthetizing the patients in the dental chair.-I am, etc.,

A. S. MODY

Anaesthetic Department,

Bedford General Hospital (South Wing),

Bedford

\section{Randomization}

SIR,--Mr. J. A. Lewis (5 July, p. 41) raises queries about the use of month of birth as a technique for allocating patients in clinical trial. He questions whether there is any real correlation between morbidity and month of birth. There is a clear association between month of birth and morbidity in infants 1 week to 2 months old with increased mortality from a range of disorders occurring in infants born during the winter months (this is shown by table 25 in the Registrar General's Statistical Review of England and Wales). At the opposite end of the age range I have recently detected an excess of deaths occurring in the month of birth and succeeding three months among persons aged 75 years and over. ${ }^{1}$ This excess, though only accounting for about $1 \%$ of the deaths, is consistent in either sex and subgroups by marital status. The excess is statistically significant and again serves as a warning of potential association between month of birth and morbidity.

However, the use of an open technique such as date of birth has other major hazards in the allocation of patients. A fundamental concept in controlled clinical trials is that the patients should be entered for the trial and once they have agreed to participate random allocation to treatment group should then occur. Use of an open technique of allocation (such as date of birth, date of hospital attendance, hospital record number) enables differential recruitment to occur into the treatment groups. There are a number of reasons why this can occur and there are some well-documented studies where gross bias has occurred because of such action. ${ }^{2}$ This latter point is a stronger argument for using an appropriate "blind" randomizing technique.-I am, etc.,

\section{Michael Alderson}

Wessex Regional Health Authority, Winchester

Alderson, M. R., British fournal of Preventive Mres. In pres.

Intolica Clinica, 1974, 16,

\section{Loperamide and Ileostomy Output}

SIR,-By chance we had to look again at the data collected during our double-blind trial of loperamide in ileostomy patients (21 June, p. 667). From this new analysis we learnt that the greater the ileostomy output the more benefit from loperamide treatment is obtained by the patient. This phenomenon is illustrated in the fig. The correlation ( $r=$ $0 \cdot 850$, Spearman rank correlation coefficient) is highly significant $(P<0.0001)$.

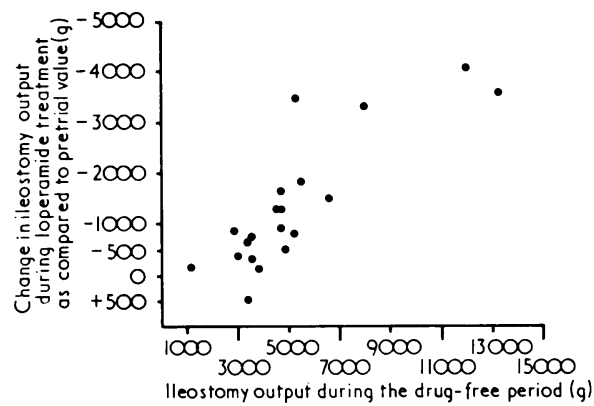

We feel that this new feature confirms our opinion that loperamide is effective in controlling excessive ileostomy losses of water and electrolytes.-I am, etc.,

Wilhelmina Gasthuis,

G. N. TYTGAT Amsterdam

\section{“Most Physicians Believe ..."}

SIR,-Your leading article on diabetic nephropathy (5 July, p. 5) states: "most physicians believe that these patients should receive the best possible diabetic control ... but it remains disappointing that there is no scientific evidence of a reward for doing so."

In medical literature we are repeatedly told that "most physicians" or "most surgeons" or "most endocrinologists" believe this or that, as if to imply that the truth is revealed by consensus. We should remember that 20 years ago "most cardiologists" believed that all the victims of cardiac infarction should be kept bedfast for six weeks, "most gastroenterologists" believed that those with peptic ulcer should be treated by graduated diets, and "most physicians" who specialized in poisoning believed that analeptic drugs saved life.

When we read an article about treatment we wish to be told about its efficacy. If there is evidence that it is beneficial this should be reviewed; if there is no such evidence or if the evidence is conflicting this should be noted. In particular, the author should distinguish between treatment based on theory and treatment based on evidence, and this is what so many lamentably fail to do. As well as urging that both you and your contributors avoid the phrase "most physicians believe," may I also urge that you cease to refer to "scientific evidence"? For this implies that there can be non-scientific evidence.-I am, etc.,

JOHN W. TODD

Farnham, Surrey

\section{Levodopa in Breast Cancer}

SIR,-I should like to comment on the E.O.R.T.C. study by Dr. Engelsman and co-workers (28 June, p. 714) describing the apparent failure of levodopa therapy in an unselected group of patients with advanced breast cancer. It seems to me that levodopa has a specific if somewhat minor role in the management of breast cancer and it would be unfortunate if it was completely abandoned as a result of this study.

All the positive reports of the use of levodopa in breast cancer refer to its value in the relief of bone pain, and this response was used for selecting patients who subsequently responded to hypophysectomy. ${ }^{1-3}$ In the E.O.R.T.C. study only six patients had bone metastases. The Westminster group ${ }^{4}$ have provided evidence that only about $16 \%$ of breast cancers are dependent on prolactin alone and about a further $23 \%$ show prolactin dependence in conjunction with other hormones. Furthermore, prolactin dependence appears to be common in premenopausal patients. ${ }^{4}$ Thus of the six patients with bone metastases, all of whom were postmenopausal, only one or two would have been expected to respond to levodopa. In my opinion a full trial of levodopa specifically in premenopausal patients with bone pain is required.-I am, etc.

University Department of Surgery,

K. K. Mahajan

\section{Minton, J. P., and Dickey, R. P., Surgery, Gynecology and Obstetrics, 1975, 136, 971 .
Minton, J. P. and Dickey, R. P., New England fournal of Medicine, 1972, 286, 843 . \\ 4 Hobbs, J. R., et al., British fournal of Surgery, $1974,61,785$.}

\section{Emigration of Doctors}

SIR,-It is interesting that a member of the staff of the Liverpool School of Tropical Medicine should write (26 July, p. 229): 